Published in Hanne Appelqvist (ed.), Wittgenstein and the Limits of Lanugage (London: Routledge, 2020), pp. $245-269$.

This is a penultimate draft. Please quote only from the print edition.

\title{
Measure for Measure: Wittgenstein's Critique of the Augustinian Picture of Music
}

\section{Eran Guter}

"Sometimes a sentence can be understood only if it is read at the right tempo.

My sentences are all to be read slowly." $(\mathrm{CV}, 65)$

To say that Ludwig Wittgenstein has a philosophy of music might appear as something of a misnomer. If we tend to understand the term "philosophy of music" rather narrowly as the philosophy whose job is conceptually to determine the object "music", then it would seem that there is no "philosophy of music" in Wittgenstein. I would like to suggest that Wittgenstein was after a kind of philosophic sensitivity rather than a body of knowledge, one which is best cultivated by musizieren, by musicmaking in the broadest sense, and so should we be, if we truly wish to see the value of his remarks on music. There is much to say about the extent and depth of Wittgenstein's thinking about music, which is spread across his Nachlass, his lectures, and other texts, both systematically and in the context of the history of ideas. Indeed, Wittgenstein should be considered as an important transitional figure from Romantic thinking about music to the modern time (Guter 2017).

Thus, in this article my goal is twofold: to give a detailed, contextually rich exposition of Wittgenstein's thinking about music and to flesh out the philosophic sensitivity which he wants to 
cultivate by means of thinking about such matters. More specifically, I trace and reconstruct Wittgenstein's understanding of the conceptual framework pertaining to musical temporality. Wittgenstein's view emerges as a sustained critique of what I propose to dub the "Augustinian picture of music". The obvious allusion to Wittgenstein's critique of "the Augustinian picture of language" (in the Philosophical Investigations) is more in spirit than in substance. The picture which holds us captive here is not that of language per se, but of time as a substance, or a space, or motion, all of which are internally experienced and identified. Wittgenstein's discussion is carried out in the context of his middle-period philosophizing (1929-1936).

I start by offering an overview of Augustine's account of time, as understood by Wittgenstein, and the latter's specific rejection of Augustine's notion of measuring in the mind. I then argue that Wittgenstein's sustained critique of "the Augustinian picture of music" actually sets him antagonistically vis-à-vis a venerable tradition in the philosophy of music by means of exposing and clarifying the many limitations of the language which has been used on pains of obfuscation and nonsensicality for undergirding this view of musical temporality. In the final part of my article, I argue that by opting to reverse the Augustinian priorities as regards temporal orders, Wittgenstein's critique underscores the philosophic importance he attributed to the very idea of the limit of language in aesthetics.

\section{Memory as the source of time}

Musical motion is perhaps one of the most fundamental, essential characteristics of Western tonal music, which is also conveniently transparent in our mundane talk about music of the kind that was so close to Wittgenstein's heart. Listening to a melody, we hear not only a beginning and an end, but also distinct motion from its beginning to its end. In such a musical unfolding, we experience the rise and fall of a melodic line, the quickening of an accelerando, the slowing down of a ritardando, the soaring 
of a modulation, and the coming to a halt of a perfect cadence. We even experience motion when no sound is heard, as in the occasional pregnant silences that are part of so many musical themes. Yet the idea of musical motion ultimately admits an apparent paradox. Musical motion seems to take place in the absence of anything that moves. It seems that if we are to speak meaningfully about musical motion as opposed to a mere series of acoustic changes, we must assume that it involves something that moves - to wit, tones - as well as something that does not move - a certain spatial frame, in which musical motion occurs.

The paradox of musical motion can be seen as the persistent shadow of what Wittgenstein called in the Big Typescript "understanding memory as the source of time" (BT, 517-518). This is the idea of time as a "mental picture", rendered as the source of our cognition and the verification of our propositions - the time of which the present immediate experience is a limit, yet a limit which cannot be mapped onto a physical system (Schulte 2006, 565). This sort of "personification of time" (M, 7:108; BT, 522) was a subject of Wittgenstein's criticism in his writings and lectures in the 1930s. Wittgenstein aimed to show that what generates the tendency to reify memory-time, to render it as a substance or in spatial terms, including the very idea of measurement, is a set of false analogies, which only generate philosophical confusion. Ultimately, Wittgenstein's criticism undercuts those conceptions of music that exclusively rely on such a reification of memory-time.

The locus classicus for this picture of time is Saint Augustine's discussion of time in his Confessions. Book XI of the Confessions consists of a sustained discussion of the paradoxical nature of the flow of time. Augustine's first step is to affirm the flow of time, for without flow, there can be neither future nor past (Augustine 1948, 191). Next we learn the first immediate difficulty with the notion of time thus understood: of the triad, past, present, and future, only the present seems to exist, since "the past now is not, and the future is not as yet" (ibid., 191). Then another immediate difficulty arises: if the present bears the mark of time, i.e. directional flow, it must become past; that is, the 
present tends not to be as it continuously flows out of existence. Importantly, Augustine links the ontology of time to time measurement. Acknowledging that we compare periods of time and measure their relative length, Augustine moves to discuss time measurement for time present (time measurement for both time past and time future drops out of consideration, since they were shown not to exist). Under the assumption concerning the flow of time, Augustine tries to close in on a "temporal atom", which cannot be divided further into future and past. Ultimately, he whittles down the time that is said to be present to a dimensionless point, which has no measurable extension (ibid., 192). Thus, Augustine portrays time as passing "from that... which as yet is not, through that which has no space, into that which now is not" (ibid., 195).

Against this backdrop, the problem of time measurement becomes acute. Augustine's escape route out of this paradoxical picture of time leads directly to music. In his treatise on music, De Musica, Augustine defines music as bene modulandi scientia, "the knowledge [science] of measuring well." According to Augustine, to be "well measured" musical motion must be in harmonious proportions; hence the true science of music rests in knowing these mathematical ratios which govern musical art. Musical rhythm is created in metrical terms when temporal modules of similar proportions are joined to form a verse or phrase. Most importantly, Augustine acknowledges that musical motion in the sense of rhythm is formed only when the chosen temporal modules are repeated (Waite 1980, 696).

We can easily recognize Augustine's theory of musical rhythm in book XI of the Confessions, as he employs musical examples in order to explain the way we measure the passing of time (Augustine 1948, 199). The measurement of time takes place in actual performance and in relative terms. The temporal units "long" and "short" do not designate absolute values but are rather grounded in comparison - the former is "long", because it is relatively longer than the latter by a fixed ratio of 2:1; and vice versa. The introduction of absolute temporal values, such as the values measured by a chronometer, upsets Augustine's conception of musical motion. Augustine contended that in music 
measuring the "spaces" of the temporal units "is not measuring by pages (for in that manner we measure spaces, not times), but when in uttering the words they pass by" (ibid., 199). For Wittgenstein, this contention epitomizes the philosophical confusion, which besets this picture of time. Augustine seems to have commingled the very different ways in which we measure time and space as he concluded that we measure the specious-present in our mind, as if the present is some object in front of him.

Since we seem to measure tracts of time in performance, Augustine concludes that "time is nothing else than extension; but of what I know not" (ibid., 199). However, measuring the extension of a tract of time cannot begin while it is future, before coming to existence, and until it is complete, having passed out of existence to become past. Sound can be measured only while it is sounding, for "while passing, it was being extended into some space of time, in which it might be measured, since the present has no space" (ibid., 199). Augustine's final resolution of the problem of time measurement gives priority to memory time: "do I not measure [syllables] themselves, which now are not, but something in my memory, which remains fixed. In thee, O my mind, I measure time" (ibid., 200). Since each syllable uttered, each sound voiced, is immediately past, to measure a tract of time by comparing it in the following act of annunciation to a subsequent one is made possible only through memory. Our attention - through the acts of remembering, attending and expecting - is a lasting thing that produces continuity in present experience (ibid., 195). As we sing or recite a psalm, time flows from future to past through this extended present experience, and as expectation wanes memory lengthens.

Thus, it is only when we identify the first tone as coming before the second tone once it is complete and the second one sounds (and by the same token, when we identify the second tone, while it sounds and later on, as coming after the first tone), that we can speak of musical motion. And this motion stretches between my expectation and my memory. In the words of Augustine, "the life of this 
action of mine is extended both ways between my memory, on account of what I have repeated, and my expectation, on account of what I am about to repeat" (ibid., 201). In other words, the paradox of musical motion can be resolved only by introducing a notion of musical time that is based on the framework of memory time.

\section{Measuring measures}

Augustine's notion of time measurement captured Wittgenstein's attention in the context of his growing interests in relativity in measurement, metrology, and his fascination (beginning in 1929) with Albert Einstein's discussion of time in terms of time measurement and clock coordination (Kusch 2011; 2015). Ultimately, the core insight of Einstein's account, as Wittgenstein understood it, was that "how a dimension is measured determines what dimension it is" (MS 107, 124). Hence, if we wish to know what time is, we need to ask how it is measured. As we have seen, this is precisely how Augustine proceeds in his discussion of time in the Confessions.

For Wittgenstein, Augustine's search for a definition for time is a paradigmatic case of being led astray by an inclination to suppose that the sense of the word "time" is governed by exact rules. Once Augustine realizes that there are certain cases where such rules cannot be applied consistently, he moves to replace what he takes to be a mistaken definition (for example, "time is the motion of the celestial bodies") with a supposedly true definition (for example, "time is a protraction of the mind").

Wittgenstein's criticisms of Augustine's discussion of time proceed along two related strands: one pertains to the standard of exactness that is embedded in Augustine's way of speaking of time, and the other to the apparent contradiction in the grammar of the word "time" that generates Augustine's difficulties with time measurement (BB, 26). Augustine's conception of time measurement generates a puzzle, which becomes manifest also in his view of music. "Solving this puzzle," says Wittgenstein,

"will consist in comparing what we mean by "measurement" (the grammar of the word 
"measurement") when applied to a distance on a traveling band with the grammar of that word when applied to time" $(\mathrm{BB}, 26)$. Wittgenstein's point is that the word "measurement" and its related standards of exactness and precision belong to the vocabulary of the physical. Augustine's conception of music as some sort of knowledge based on demonstrable data, whose subject matter are temporal units based on memory shows precisely the kind of grammatical confusion involved in any attempt to use physical vocabulary in the realm of immediate experience.

Wittgenstein suggests another formulation of the false analogy: the "river analogy". The Augustinian question "where does the present go when it becomes past?" arises most easily when we are preoccupied with cases in which there are things flowing by us - as logs of wood float down a river. We then use this simile for all happenings in time (BB, 107-108). Insofar as they are built into our language in some sense, the travel band and the river analogies seem to allure us into thinking of temporal events as fixed points or entities coming towards us as we expect them, passing us by as we experience them, and then flowing away from us as we remember them. We are then tempted to think not only that we can measure, as it were, the distance between these events, but also - as strongly suggested by the picture of the floating logs of wood - that we can measure the length of each event.

It is not hard to see how susceptible music can be to this model of time measurement. We readily accept the picture that a melody consists of audible events that we anticipate before we actually can hear them fading away into the deep recesses of our memory. The river analogy goes as far as prompting us to employ spatial concepts when we speak of tones that are heard higher or lower than others, that they occur in tandem (like two logs of wood floating side by side), or that the various voices in a contrapuntal formation pull to different directions. Moreover, the river image itself allows the analogous opening of a spatial framework in which tones are attended to as they are in themselves, as if they were floating logs of wood. 
Like in case of the logs of wood that float on the river, we measure not only the relative length of the tones that pass us by, but also the intervals of silence between them. Modern musical notation provides a very clear and elaborate representation of these duration values. Furthermore, we attach such an importance to the regular flow of the "melody river" that we are genuinely surprised, at times even annoyed, when we hear that a tone arrives too late or too early. In such cases we say that our expectations were not fulfilled. Oftentimes this might be just a matter of the music being played incorrectly, and on very rare occasions among great composers this might also be a result of a miscalculation in the construction of the music. Notwithstanding, the history of Western music has witnessed the development of numerous techniques for upsetting the regular flow of musical time from the earliest employment of recitativo in the $16^{\text {th }}$ Century to the latest syncopated Jazz - that have risen to the highest level of artistic significance. Most importantly, we speak of a melody as something, which has a beginning and an end that demarcate a (more or less) finite number of temporal units (tones and silent intervals). Finitude is probably the most trivial yet utterly peculiar characteristic of concrete pieces of music (as opposed to whatever we may mean by "the music of the spheres", for instance).

A piece of music has a beginning and an end. At least within the realm of common compositional practice, these boundaries are musical boundaries, not arbitrary time indexes that merely delineate certain duration, as it is the case in John Cage's notorious piece 4:33. It would not be unusual to observe a conductor asking the members of his orchestra during a rehearsal of a symphony to repeat the last 100 measures before its end. In such a case there will be 100 more measures and that will be the end, and indeed we might conceive of an experience which would verify these statements: a final majestic tonic chord played in full-fledged tutti, then silence, and then scattered clacks of bows hitting metal music stands in acknowledgment of the conductor's inspired rendition. More important yet, one would simply hear that the music reached its end. The fact that the Swiss-made hand-watch on the 
conductor's wrist never stopped measuring time even after the last musician has left the rehearsal hall is of no consequence here. Since we have been following measures, and since the measures came to an end, time in this sense - to wit, musical time - ceased when the symphony ended.

In his lectures in Cambridge during 1930-1933, Wittgenstein offered an elaborate discussion of the river analogy, which illuminates the strangeness of the finitude of musical time (AWL, 14). If we think about time in terms of the river analogy, and think that times ceases, then we might say that "time ceases when 'Time River' ceases". He suggests that we could drop the idea that we have the substantive "time", and just talk of the passing of logs. In this sense, "we could talk of time coming to an end, meaning that the logs came to an end".

\section{The Augustinian picture of music}

Augustine's discussion of time qua substantive gave rise to a philosophical picture of music as embodiment of "time as the source of cognition", to use Wittgenstein's words. This is a picture of music as "the personification of time": musical motion is rendered as something which is subjectcentered, felt inwardly, internal to the specious present - a duration, or a flow, which is experienced as the passage of life itself, measurable only in terms of sensibilities, tensions, and emotions. That which is to be understood in, and also as music - form and expression alike - is thus patently related to such inner movement. The only real present in music is punctiform, stretching in the mind between memory and expectation. Musical time occupies its own space, which is voluminous, complex and variable in a way which makes it utterly unlike metrical time.

In the Augustinian picture of music, musical time is contained in the specious present, hence we rely exclusively on the conceptual framework of memory-time in order to make sense of the extent of virtual imaging backwards, to what is retained in our mind, and forwards, to what we anticipate. We can compare this patently perspectival mode of identifying the musical object (in this sort of direct 
experience of time) to a "searchlight", following a suggestion made by J. D. Mabbott (Mabbott 1951). The constant span of illumination of the searchlight (representing the span of the specious present) moves continuously parallel to, and along, its postulated "target" (i.e. the music) as it "illuminates" it.

The Augustinian picture of music underlies a venerable tradition in the philosophy of music, which openly attaches the paramount profundity of the art of music to its embodying of the nature of time "as the source of cognition". The general characteristics of this sort of "searchlight" conception of musical time are manifested spectacularly by distinctly different representatives of this tradition, for example, Edmund Husserl in The Phenomenology of Internal Time-Consciousness (Husserl 1964), Susanne Langer in Feeling and Form (Langer 1953) and most recently Jerrold Levinson in Music in the Moment (Levinson 1997).

Wittgenstein went to the heart of the Augustinian picture of music in his debunking of Augustine's contention that the word "now" is a specification of time, a name of an instance of time, a real punctiform present. This is where that picture seems to hold us captive, yet according to Wittgenstein, the error is already contained in Augustine's initial question “what is time?”, which presupposes that in some sense time is made of some material (BT, 522).

Thinking about measuring time by means of the river analogy is symptomatic of our preoccupation with cases in which there are things flowing by us. The analogy leads us to render the "present moment" as one such thing. But "what does one mean by the "present moment"'? Wittgenstein asks, "This idea is already based on a physical image, that of the stream of experiences that I'm now bisecting at a point" (BT 494). Augustine's discussion of time is an attempt to come to terms with the question "where does the present go when it becomes past?" For Augustine, the present moment leaves a kind of temporal space behind its own disappearance. This is the reason, he thought, why it can be measured presently as having occurred in the past. Wittgenstein's reaction to this is biting: 
It's strange that in ordinary life we are not troubled by the feeling that the phenomenon is slipping away from us, the constant flux of appearance, but only when we philosophize. This indicates that what is in question here is an idea suggested by a misapplication of our language. (PR, 52.)

Augustine's original puzzlement concerning the nature of time is a prime example for language being seduced by substantives as it runs against its own limits. The "personification of time" arises when we extend language by only looking at language instead of using it practically (M, 7:108). Importantly, Wittgenstein says in this context, "when we hand over the reins to language and not to life, that's when the philosophical problems arise" (BT, 522; my emphasis).

The very idea of time qua temporal space, and with it the captivating idea concerning the flow of time (within that space), sidelines the way we use "time" as a temporal ordering of events. "It's just we've used a simile," Wittgenstein wrote, "and now the simile is tyrannizing us. In the language of the simile, I cannot move outside of the simile. Wanting to use the language of this simile to speak of memory as the source of our cognition, as the verification of our propositions, has to lead to nonsense" (PR, 49; BT, 518). Wittgenstein's point is that we need to observe a limit: we cannot apply the concept of time, i.e. the grammatical rules as they apply to physical nouns, to the world of mental imagery, where one uses a radically different way of speaking: "For 'time' has one meaning when we regard memory as the source of time, and another when we regard it as a picture preserved from a past event" (PR, 49). For instance, saying that we have perception into the past (as we do in the framework of memory-time) contradicts every concept of physical time (PR, 50). Also, the idea of the specious present invites us to regard the future as pre-formed in some sense. This is very characteristic of the philosophies of music, which I mentioned above. Wittgenstein points out that "there is a point in saying future events are pre-formed if it belongs to the essence of time that it does not break off" (PR, 51). 
Yet, not breaking off is characteristic of the framework of physical time. The present in memory-time is patently slipping away from us.

One of the images, which Wittgenstein used occasionally during his middle period in order to tease out this sense of limit for our language of time, is the film-strip analogy (PR, 49-54; M, 8:49-50; BT, 494-498, 518). Wittgenstein suggested to think about the present experience as a picture on a filmstrip. There are two alternatives here: either to talk about the projected image, or else to talk about the picture on the film-strip itself. In the latter case, there are other clearly identifiable pictures preceding and succeeding it on the strip. Wittgenstein's point in this analogy is that the philosophical idea that "present experience only is real" - the crux of the Augustinian picture of music - arises from imagining events to pass before us like film in a projector, or lantern. When the image is there and seen, no other image is there and seen. "It would be all right, in case of lantern, if pointing to one picture of the film we say 'this is the only one which is in the lantern now': and we could call this 'real'", says Wittgenstein, "But if he pointed to screen \& said 'this is only real picture' he would talk nonsense, because it has no neighbours" (M, 8:49). Wittgenstein extended the film-strip analogy also to music by imagining also a film with soundtrack. Again, the point is that what produces the music is part of the film-strip (PR, 70; BT, 496).

As Joachim Schulte points out (Schulte 2006), the film-strip analogy is closely related to the theme of solipsism in Wittgenstein's middle-period, and in an important sense for our present concern, as we shall see in the following sections. According to Wittgenstein, there are modes of talking about present experience in which we can, and sometimes ought to dispense with the word "present", just like we can sometimes do without the word "I". In such contexts (e.g., when we cannot speak of the present as opposed to past and future), the word "present" seems to cancels out simply because there is no other word, which could replace it. In such context, the word "present" does mean something bordering on something else, from which it can be limited off. Wittgenstein's upshot is very clear. At the heart of 
the Augustinian picture of music we might find an idea which is akin to "the picture on the screen which would illegitimately be called present, since 'present' would not be used here to distinguish it from past and future. And so it is a meaningless epithet" (PR, 54).

Wittgenstein's critique of the Augustinian picture of music is given a striking pronouncement in the context of Wittgenstein's consideration of C. D. Broad's theory of our awareness of the temporal extensity of the immediate objects of our experience (Broad 1923). Broad argued that at a given instant we are directly acquainted with a temporally extended sense datum, which occupies a short interval of time "stretching" into the past from that instant. He also argued that the sensing involved in our experience of a long musical tone and the aural-sensum with which we are acquainted are both continuous.

Again, Wittgenstein makes a move characteristic of his middle period: distinguishing between different kinds of logical or grammatical "spaces", pointing out analogies and dis-analogies between them, and stressing that what could be said of the concepts which belong to one such space could not meaningfully be said of concepts belonging to another space. Wittgenstein's point here is that word "continuity" belongs strictly to the vocabulary of the physical world. When we apply the physical notion of continuity to our immediate experience of a musical tone we end up precisely with a "searchlight" model of music. Wittgenstein is on record for rejecting this model in the most straightforward way: Can you in a continuous sound distinguish the part you are hearing at the moment and the part you remember hearing? You can hear a click, and there is no part of it which you can remember as coming before or after another part; whereas with a sustained violin note you can remember the part which has gone before. The problem then is to find an intermediate stage at which you can say that you both hear and remember. (LWL, 71.)

The "intermediate stage at which you can say that you both hear and remember" is the musical specious present in which actual hearing and vivid remembering (and anticipating) coexist. According 
to Wittgenstein, the confusion lies in thinking that physical sound and the sense-datum are both continuous. The physical sound is continuous, but the sense-datum is not. The two experiences, hearing and remembering, are quite distinct. You can narrow down the point between where you finish hearing and where you begin remembering, but there will be no point at which you can say you both hear and remember. (LWL 71-72.)

Wittgenstein makes it very clear that a notion of continuity based on memory-time is nonsensical, and his argument - apparently a direct rebuttal of C. D. Broad's position - undercuts the very foundation of the Augustinian picture of music.

\section{The Janus-face of musical time}

Wittgenstein's river analogy intimates the Janus-face of musical time. The steady pace of the traveling band or the constant flow of the river, and, at the same time, the possible unevenness in the spread of the logs of wood across the water, the differences in their relative velocity, or their varied size; and, of course, their finite number. One face speaks of meter: an order of time which is regular, chronometric in the sense that it is determined and verified by means of publicly observed criteria (for example, metronomes), and open-ended in the sense that it does not entail any structure. The other face speaks of rhythm: an order of time which is malleable in the sense that it is subservient to a musical contour, hence integral to it, admitting a mode of identification that is primarily subject-centered.

To elucidate this bifurcation, let us ponder a little the clicking of a metronome. On the one hand, the evenly spaced clicks of the metronome serve the same purpose as any other time measuring device. Set it to $60 \mathrm{bpm}$ (beats per minute) and it would virtually replace any regular stopwatch (one might say, our lives are set against the resolute beating of a secret larghetto). Musicians use the metronome primarily to determine a tempo, namely, the sheer velocity in which a musical performance ought to proceed. Strictly speaking, if we play the same piece of music first adagio $(66-76 \mathrm{bpm})$ and 
then allegro (120-168 bpm), the latter performance should take roughly half the duration of the former. Thus, the regularity of meter is essentially chronometric. On the other hand, the clicks of a metronome mark also a distinct accent, and, as David Epstein points out, it is the manner of this accent - its marked articulation, the quick onset lacking the capacity for broad expressive character - not necessarily its durationally equal spacing, that is of utmost significance to the character of beat, the primary level of meter (Epstein 1995, 29).

Yet counting has a special character in music. Following the clicks of a metronome, musicians do not count "one, two, three, four, five..." and so on ad infinitum, but rather periodically: "One, two, one..." (for duple meter); "One, two, three, one..." (for triple meter); "One, two, three, four, one..." (for quadruple meter), etc. The periodicity of musical meter gives rise to the musical measure, which is represented in modern musical notation by bar lines. However, there is nothing in the accent of the isochronal, equitonal clicks that would prompt us to parse them one way or another, and, in effect, to count "in a closed system" (see RPP I, 647). We certainly can, and do, use the metronome or any other time measuring contraptions to count at will in any of the aforementioned ways as well as in many other ways. Yet when we do count "in a closed system" following the clicks of a metronome we acknowledge a periodic accent on what we take to be the first beat of a metrical group. "The knowledge of metre," Wittgenstein wrote, "One who knows the metre, hears it differently" (RPP I, 746). Thus, the periodicity of the musical meter is informed by our knowledge of a further musical element: pulse. Pulse, the primary durational level of rhythm, is the complementary unit to beat with regard to meter. In contradistinction to the chronometric beat, pulse is enlivened and shaped by the wide variety of onset qualities that give rise to accent, which is, to quote from Roger Scruton, "the primary form of rhythmic emphasis, the bringing forward into consciousness of a particular moment in the rhythmic order" (Scruton 1997, 29). Here we approach that which pulsates, throbs, swells, and lilts in music. By 
counting in musical meter, we move beyond the realm of the chronometrically measured into the realm of the rhythmically alive.

This is precisely where Wittgenstein diagnoses the kind of grammatical confusion involved in any attempt to use physical vocabulary in the realm of immediate experience. "The moment we try to apply exact concepts of measurement to immediate experience, we come up against a peculiar vagueness in this experience," Wittgenstein wrote, "But that only means a vagueness relative to these concepts of measurement. And, now, it seems to me that this vagueness isn't something provisional, to be eliminated later on by more precise knowledge, but that this is a characteristic logical peculiarity" (PR, 211). This is splendidly embodied in the performance of so-called "non-linear tempos", such as tempo rubato, accelerando, and ritardando. In the simplest terms, rubato performance involves a certain distortion in musical time, the expressive alteration of tempo and rhythm within a bar, a phrase or even an entire movement. Tempo rubato - "stolen time" in Italian - means that time in rubato performance is robbed from one part of the music, arguably to be paid back elsewhere. An expressive quality is achieved by giving more duration to certain notes in the melodic figure and then compensating the stolen time by shortening notes in another part of the bar or phrase. Underlying this concept of rubato is the notion that a phrase played in rubato should not take more time than the same phrase played in strict time.

In Romantic rubato, the pull of expressive rubato in melody eventually overpowers the musical complex, with the result that an entire passage in all its elements - melody, harmony, and rhythm - would be drawn out of rhythmic shape as particular segments are compressed or extended in their duration. Yet which time is stolen and paid back in rubato performance? Certainly not the chronometric time of metric beat, which maintains its regular, steady, unchanging, indifferent, mechanistic pulsation throughout the rubato passage. Rather, the term tempo rubato refers to the temporal malleability of the musical contour, to the significantly irregular pull that leads us, or guides 
us - performer and listener alike - from one side of the metric chasm to the other. A successful rubato performance is quite an artistic feat. Like in a daring acrobat's act, much of its suspense and gratification lies in the prospects and the ability of the performer to land with grace and precision on the right spot, namely, the phrase end, which in its timing is simultaneous with the attack on the next phrase.

Thus, we have two aspects that are dialectically intertwined in a rubato performance: significant irregularity and precision. The former without the latter is a meaningless spasm; the latter without the former is a mere mechanical reproduction. As Scruton aptly put it, "rhythm plays with regularity, but is not reducible to it: the pulse is both counted and discounted" (Scruton 1997, 24). Rubato makes sense only on the assumption that, in a sense, the beat is measured out. In rubato performance we have a dramatic display of two different systems of time control, two kinds of time measurement, operating simultaneously, as they rapidly become dis-synchronous and thus in conflict only to realign at the phrase end (see Epstein 1995, Ch. 11). On the one hand, we have the metric control of the beat, which is precise and chronometric, and on the other, we have the contorted pulse that leads us away from the regular beat and back. These two senses of time differ significantly from one another by their respective means of verification hence by their respective means of measurement. The verification of the former rests on the regularity of any time measuring device - a metronome, a stopwatch, even steady foot tapping - while the verification of the latter rests on the recollection and anticipation of the particular phrase structure in its particular performance.

We may conclude that different musical elements - the way we perform them, express them, and in general, understand them - are geared toward two different conceptual systems of time. This amounts to saying that these different musical elements are respectively governed by different grammars. It is the clarification of this grammatical difference that is crucial in Wittgenstein's thinking. 


\section{Two orders of events}

According to Wittgenstein, in a language in which there is only "before" and "after", but not past and future, "personification of time would not have occurred" (M, 7:108). So unless we are in the grip of a picture - such as the Augustinian picture of music - which persuades us to think of time as personified, we need to acknowledge that what we call "time" in our variegated language-games is rather the ordering of events. "An order could be established," says Wittgenstein, "without knowing what it was about. We might call it 'grammatical' time" (M, 8:64). Wittgenstein distinguishes between two independent orders: memory-time and information-time.

Viewed as an order or a system of reference, not as a temporal space, memory-time is the specific order of events or situations in my memory. It not part of time in the larger sense (große Zeit; BT, 521). Memory is relative to the moment of time at which the remembering takes place. This means that memory-time is a now-centered system of time-references. In such a system, there is only "before" and "after", "earlier" and "later", but no "past" and "future”. Wittgenstein points out, significantly, that "in my memory there is a direction from more remote to nearer, which I might call direction towards the present - which I might call "memory-present" analogous to eye in visual field" (M, 8:39). In this order it makes no sense to say of a given event that it "occurred after the present in memory-time" (PO, 112). Furthermore, the order of memory-time, when taken in isolation, cannot rely on any external criteria for time-reference or time-measurement. According to Wittgenstein, the mere internal description of my memory will not show any difference between my memory and other people's. The only difference will be relative to a public system of references, namely, informationtime (M, 7:106). Memory-time can rely only on one's current memories and expectations. Yet such references do not seem to give us any direct way of measuring time-spans.

In contradistinction, Wittgenstein suggests to look at another order of events, involving the specification of time-references by means of public, observable chronology, which is implemented not 
only by means of chronometers and calendars, but also by means of documents, diaries, manuscripts, and other modes of making records or consulting them. Information-time is "the order in which information is got by asking different people" (AWL, 15). It is observation-time (M, 7:106), writtentime (M, 8:64), narrative-time (M, 8:45), historical time (BT, 495), and the time of documents (M, 8:49). More narrowly it is also physical time (BT, 495). It is the order of the film-strip, in which "before" and "after" spell also "past" and "future" (M, 8:46). "With our language," Wittgenstein writes, "we find ourselves, so to speak, in the domain of the film, not of the projected picture" (PR, 70). Schulte makes a helpful suggestion that the game of asking for and receiving information is a variegated activity (significantly less predetermined system than physics and its applications) and that Wittgenstein's middle-period conception of information-time is pioneering in the sense that it could be taken as a move toward the rich variety of language-games in the form it is presented in Philosophical Investigations and in Wittgenstein's other later writings (Schulte 2006, 566). In this sense, Wittgenstein's emphasis on information-time is an attempt to resolve philosophical conundrums pertaining to an exclusive reliance on the order of memory-time, for instance, temporal solipsism (see Hintikka 1996, 242-243). For Wittgenstein, "the process of 'language' runs its course in homogeneous historical time" (BT, 495).

Wittgenstein makes it clear that "we have to give up the view that in order to speak about the immediate, we must speak about a state at a moment in time" (BT, 494). However, in our actual language there is hybrid order: 'If I say: 'before' \& 'after' mean something different, when you use memory as criterion, \& when you use documents, I'm referring to 2 games, which are never played in their purity" (M, 9:49). If the two games (exemplifying the two orders of events respectively) are never played in their purity, then a need arises to ascertain priorities in our language: the order of information-time must be prior to the order to memory-time - a reversal of the Augustinian priorities. The reliance of information-time on public, observable criteria lends it the kind of multifarious 
complexity, which is familiar to us from major themes in Wittgenstein's later philosophy. This is shown by Wittgenstein's frequent use of metrological models and analogies for understanding ideas or phenomena in other domains, such as language, mathematics and the study of certainties (Kusch 2015). As we have seen, Wittgenstein argued against Augustine's view of time measurement that the word "measurement" itself, and its related standards of exactness and precision, belong to the vocabulary of the physical world. Yet, as Martin Kusch points out (Kusch 2011; 2015), Wittgenstein gradually came to realize that "methodology" (metrology), is "a description of the activities called 'measuring', a branch of human natural history that helps us understand the concepts of measurement, precision, etc. in all their variants ..." (MS 135, 129). The very standards of exact measurement are entrenched in social institutions, as shown, for example, by Wittgenstein's well-known discussion of the "Parisian Standard Meter”, deposited in the French Archives in 1889 (PI §50; RFM, 36). To be familiar with the standard meter requires that one is "acquainted with the institution of measuring and its connexion with the standard meter" (RFM, 36). Wittgenstein's point is that in order for something to be a unit or standard of measurement, it needs to have a social status within an institution. This idea links directly with Wittgenstein's consideration of rule-following, in particular the problem of the regress of rules, that is the apparent need to deposit in the archive not only the standard for measuring, but also rules for comparing the standard with tokens of that type, and rules for using such rule, and so on infinitely (LFM, 106; see PI §201). According to Wittgenstein, the regress stops due to the fact that we establish by means of training a more or less uniform practice on the basis of what is in the archives and what is available in the institution of measuring.

\section{The "physical ear", the "auditory ear" and the aesthetically "right"}

Wittgenstein's emphasis is on "now", not as a "specification of time", a name of an instance of time, but as "ligature to reality", whereas "the reality that belongs to a symbol in this way falls under the 
domain of grammar" (BT, 525). His ultimate point is that we need to look at the whole language game in which the word "now" plays a role, instead of just looking at the contexts, the phrases in language in which the word is being used $(\mathrm{BB}, 108)$.

In music, the word "now" and its manifold preparative gestures (a deep breathing in, a meaningful glance, a nod, a thrust of the conductor's baton) prefigure musical simultaneity, which features primarily in the context of musizieren, of music-making in the most inclusive sense (see KL, 37; RPP, I 1130).

Wittgenstein's discussion of the word "now" (during his middle-period) is linked with his consideration of other "ligatures to reality" such as the words "here" and "this" (see e.g. BT, 523-527). In this context, he repeatedly makes the distinction between two kinds of criteria, which he dubs respectively "the geometrical eye" and "the physical eye" (e.g., BB, 63-64). The physical eye, quite simply, is the biological mechanism we use to see objects in physical space, where rays of light converge etc.; the geometrical eye is the place from which visual space is seen, which is determined by one's pointing at it. The important difference between these two "eyes" is in the way we use them to identify and verify objects. We use the physical eye to name and locate objects in physical space, while we use the geometrical eye to pinpoint the contents of our present visual experience. The former is carried out publicly by pointing to an object in the room and saying "the second book from the right on the bookshelf, the one with the blue cover", while later is carried out by ostension as we say "here!" or "this!"

Wittgenstein's point is that while the two eyes, the physical and the geometrical, usually coincide, it is conceivable that the aforementioned foci do not (see Stern 1995, 76). Importantly for our present concern, Wittgenstein quite naturally extended this distinction into the realm of musical experience: “Change of pitch or intensity does not require any 'auditory ear'. For movement of sounds what is needed is a 'system of co-ordinates' which might be called 'auditory ear'” (M, 8:35). In a way 
that is analogous to the distinction between the physical eye and the geometrical, we have here a distinction between two criteria for temporal location: the one is physical (hence chronometric), namely, a physical ear; the other is integral, "a system of coordinates", namely "an auditory ear". Using the physical ear we publicly measure and time sonic objects that persist in physical time by means of institutionalized devices such as clocks and metronomes, and give exact identification of temporal locations like, "it is 6:07", or "you are exactly two milliseconds off the beat" (think of Karlheinz Stockhausen's electronic music, if you like). Using the auditory ear we refer to a temporal location that is integral to the contents of our present aural experience, saying "now!" when we hear an accented beat or describing the accented beat as "sandwiched" between a preceding long interval and a following short interval, or, as in the case of a perfectly executed rubato, landing with grace and precision at the phrase end, that is, simultaneously with the attack on the next phrase. Wittgenstein maintained that while "now" is not a name for an instance of time, presupposing a privileged, independent framework for identifying objects of immediate experience (i.e. the framework of memory-time), we do need a way of expressing the phenomena of immediate experience separately from experiences of another kind (MS 113, 247-248; BT, 496).

In order not to fall prey to the image of musical experience as a kind of, say, seashell that everyone carries with him close to his ear, and to the corresponding specter of a metaphysical owner for each such seashell, we must circumscribe the grammar of the auditory ear. That is, we must acknowledge that our utterances about our musical experiences (the order of memory-time), if they are to be used meaningfully, must rely the framework of our ordinary language (the order of information time). The upshot is this: according to Wittgenstein, the auditory ear cannot have primacy over the physical ear. To carry out its job, the auditory ear must rely on the publicly identifiable means of the physical ear. 
This is Wittgenstein's reversal of Augustinian priorities, the upshot of his critique of the Augustinian picture of music. This reversed hierarchy (namely, that information time conceptually precedes memory-time), which obtains, according to Wittgenstein, between the physical ear and the auditory ear ultimately means that in music the use of the language of memory-time is subordinated to, or rather circumscribed by the language of information time. That is, our conception of musical elements - the way we perform them, express them, and in general, understand them - must acknowledge and manifest this grammatical caveat, if it is to make sense. In particular, the very notion of "measurement" and related concepts such as "precision" and "simultaneity", can meaningfully describe musical experience only if governed by the grammar of the physical ear.

However, in the context of musizieren, and in light of what I described above as the Janus-face of musical time, this caveat is an onset for aesthetic puzzlement. As the aforementioned case of rubato performance suggests, certain expressive musical elements are geared toward the framework of memory-time while other - those responsible for clockwork execution of certain aspect of the musical performance - are geared toward the framework of information time, in particular physical time with its time-measuring devices. This bifurcation is shown in the different systems of time control that are implemented in musical performance. Wittgenstein was acutely aware of this. For him, the musical "now" is a ligature to the aesthetically "right", to a (possible) resolution of an aesthetic puzzle. In music, "now" betokens a conversation among music-makers, it belongs to a whole language-game, wherein reasons are given to the effect that one hears differently, hence one also plays differently. Consider the following two striking passages, where Wittgenstein goes straight to the heart of the matter:

A language, which is spoken on the beat [im Takt geredet wird], so that you can also speak according to the metronome. It does not go without saying that music could be paced, like 
ours, at least occasionally, by a metronome [metronomieren läßt]. (Playing the theme from the $8^{\text {th }}$ symph. exactly according to the metronome.) (CV, 85, 14.11.1948; translation modified.)

The simultaneity [Zeitgleichheit] of the clock and simultaneity in music. They are by no means equivalent concepts. Playing strictly according to the measure [Streng im Takt gespielt] does not mean playing exactly according to the metronome. But it would be possible that a certain kind of music should be played according to the metronome. (Is the opening theme <of the second movement $>$ of the $8^{\text {th }}$ symphony of this kind?) (CV 92, 30.1.1949; translation modified.)

The philosophically important concept in these two passages is the German musical term "Takt", which singularly embodies the Janus-face of musical time. The term is employed at the same time on three intricately interrelated, yet importantly distinguishable strata pertaining to musical time. First, it concerns the level of the beat, that which divides time into spans of equal duration. Beats can be indicated by time-keeping devices, such as a metronome. Second, it concerns the level of the measure, that is, the demarcation of a certain quantity of beats according to a given meter by means of bar-lines. The term "meter" is both a synonym for a time signature (again, relatable to time-keeping devices), but also denotes a structured attending to time, which allows the listener to have precise expectations as to when subsequent musical events are going to occur. As such, meter is an aspect of musizieren. Third, it concerns the realm of rhythm, the ordered time, which is, as Wallace Berry points out, is "the sum of a broad range of factors each of which is in some way a manifestation of pace and grouping, the former a product of relative frequencies of events, the latter of their relative qualities and the means by which they are unit-ordered" (Berry 1987, 305). Thus, whereas meter is a mode of attending, rhythm is that to which we attend (Gjerdingen 1989). 
In these two passages, Wittgenstein underscores the grammatical difference between the two faces of musical time: the "now" of the physical ear, and the "now" of the auditory ear. For the physical ear, the word "now" is used most significantly to synchronize and calibrate actions as well as time-measurement devices. Measuring devices, such as clocks and rulers, can be rigid and reliable when we continuously update and calibrate them against each other. According to Martin Kusch, the way in which Wittgenstein, from 1929 onwards, leans on Albert Einstein's clock-coordination as a metaphor for rule-following supports an analysis of measuring in sociological rule-following terms (Kusch 2015). The practice of measurement is communal. This illuminates an important aspect of the simultaneity of the clock:

[C]ould we talk about minutes and hours, if we had no sense of time; if there were no clocks, or could be none for physical reasons; if there did not exist all the connexions that give our measure of time meaning and importance? In that case — we should say — the measure of time would have lost its meaning (like the action of delivering check-mate if the game of chess were to disappear) — or it would have some quite different meaning. (RFM, vii 18.)

The clocks have to agree: only then can we use them for the activity that we call "measuring time". It is wrong to say that if there were no such agreement then the results of our measurements would be false. What we should say is that in that case there would be no such results. (MS 123, 19v.)

As Kusch points out, the concept of time is inseparable from the notion of simultaneity. Hence, we need to acknowledge that a single clock cannot be meaningfully said to measure time. Any given clock can measure time only if there is a protocol that links it to others (Kusch 2011).

Kusch's point is well taken. Indeed, as Wittgenstein's own comparison (in CV, 92) makes eminently clear, the concept of time is inseparable from the notion of simultaneity also for the auditory ear. The difference is precisely in the conception of simultaneity in music. It is not equivalent to the 
simultaneity of the clock. Comparing the two frameworks, the physical ear (pertaining to timemeasuring and time-keeping by means of a clock or a metronome) and the auditory ear (pertaining to musizieren), we can say that the former can be seen as some sort of abstraction. On a common-sense level, chronometric time is the only adequate scheme we know of for synchronizing practical affairs, dating past events, and constructing some perspective of future ones (see Langer 1953, 111). Precision (for instance, in the sense prevalent in science) comes with a systematic refinement of this commonsense framework. However, as I argued above, the problem with the Augustinian picture of music is the insistence that the auditory ear "is incommensurable with the progress of common affairs" (ibid., 109), hence the tendency, which Wittgenstein was adamant to resist, to hold on to the picture of memory-time as "the source of cognition".

Wittgenstein's critique of the Augustinian picture of music, and the ensuing reversal of Augustinian priories, shift our focus to the "protocol" (pace Kusch), which enables the conception of simultaneity in music. My upshot is that, for Wittgenstein, such "protocol" inheres in musizieren, in the aptly collaborative quest for drawing in significance by means of the phrasing and re-phrasing of a passage in order to characterize it, enabling by means of such comparative investigation meaningful distinctions between right and wrong.

The musical example, which Wittgenstein suggested in parenthesis in both CV 85 and CV 92, seems to have been carefully chosen to bring out the philosophical peculiarity in the kind of music for which it would indeed be aesthetically "right" to play it exactly according to the metronome. The example alluded to by Wittgenstein is the opening theme of the second movement of Beethoven's eighth symphony in F major, op. 93. From a motivic perspective, the theme is structured in short figures, each of which consists of characteristic interval and characteristic rhythm. The theme itself is brief and sparse, consisting in dense repetition of the rhythmic figuration. Beethoven deliberately restricts the use of developmental devices, resorting mainly to transposition with hardly any digression 
from the original rhythmic pattern. From a formal perspective, there is also a deliberate restriction on development, which is actually quite atypical to Beethoven. He eliminates the development section of what should have been a sonatina form. In effect, the thematic density and these compositional restrictions undermine the musical dimensions of expressivity, flow, and structural flexibility. Merely repetitive adjacent musical statements with no hierarchy allow no escape from mechanical, rigid pulsation. So, this is truncated music, structurally coerced into metronomic precision by means of reducing musical elements, which would otherwise enliven musical performance. In other words, the peculiarity, which drew Wittgenstein's attention to this example, lies in the forced coinciding of the "now" of the physical ear and the "now" of the auditory ear, that is, the chronometric fixity of the "now" of the auditory ear, which is used in the movement to a particularly light-hearted, humorous effect. It is noteworthy that this movement is commonly regarded, with some biographic support, as some sort of musical parody on the expense of Johann Nepomuk Mälzel, the inventor of the metronome (and some other mechanical curiosities), who was a friend of Beethoven.

With this example in mind, one can see clearly what is so strikingly odd about Wittgenstein's suggestion to imagine "a language, which is spoken on the beat, so that you can also speak according to the metronome" $(\mathrm{CV}, 85)$. There are some fundamental differences between rhythm in spoken language and rhythm in music (see London 2001, II:2). Speech consists of phonological segments that have their own intrinsic durations and durational relationships. Segments and phrases are separated by pauses of variable length. Patterns of stress or accent are found only within the context of a breath group or subgroup. Normal speech is only locally rhythmic, whereas in music one normally fits successive motifs and phrases into a common, continuous metric framework. Thus, in Wittgenstein's imagined metered language, the normal rhythms of speech are bound to be seriously distorted, mainly by lengthening vowels but also by fitting the segmental pauses of speech within the constraints of the meter. 
The analogy between such imagined metered language and the example from Beethoven's eighth symphony is clear. As in the musical example, also for the metered language to make sense (that is, to sound "right"), the various elements must be deliberately grouped and organized in such a way that non-metered speech would be incredulous - it would sound "wrong". The belabored strangeness of such metered language is a foil for appreciating Wittgenstein's contention that "it does not go without saying that music could be paced, like ours, at least occasionally, by a metronome" $(\mathrm{CV}, 85)$ and that the simultaneity of the clock and simultaneity in music are "by no means equivalent concepts" (CV, 92). In fact, elsewhere Wittgenstein put an emphasis precisely on the opposite type of cases: on the "meaningful irregularity" of "phenomena with speech-like character in music" (CV, 40; translation modified). Wittgenstein's example, again from Beethoven, is illuminating for our present discussion: the double bass recitative in the fourth movement of Beethoven's ninth symphony. Beethoven casts the recitative in triple meter (a strong beat followed by two weak beats with no further inner division), which tends to restrict, or perhaps overpower, the flow of the recitative much more than would a duple meter. To preserve the character of the recitative in performance, one would be inclined to "stretch" the notes that fall on the weak beats while running the risk of compromising the strict meter.

Ultimately, when the music is not truncated as in Wittgenstein's example from Beethoven's eighth symphony, "playing strictly according to the measure does not mean playing exactly according to the metronome" $(\mathrm{CV}, 92)$. Playing strictly according to the measure is couched in terms of the meter, not as a time signature for the metronome, but as a mode of attending (by the performers and the listeners), and in terms of rhythm as the ordered time attended. It is geared toward the auditory ear. The concept of simultaneity in musical performance is rough and vague in relation to our techniques of representation; yet as such it is needed to characterize our experience. Simultaneity in music requires from the musicians to attend aspects of music, which are not explicitly contained in the notation. They must attend complex aspects of timbral differences between instruments, and the different kinds of 
attack for different instruments, and the acoustics in actual spaces. They also need to exhibit sensitivity to the appropriate musical style, an understanding of the period and the appropriate performance practice for the period, as well as sensitivity to musical form and to pitch hierarchy within the musical language. The pacing of a metronome cannot guarantee the mutual alignment of all these elements. In fact, the use of a metronome can often disrupt an attempt to play strictly according to the measure (as in the aforementioned case of a rubato performance). Musicians may use the metronome "open-endedly" in order to verify or agree on a tempo. Once this goal has been achieved, the metronome is usually turned off so as not to obstruct the music.

One of the crucial elements in any successful management of musical time is achieving the "right" tempo in performance. The concept of tempo itself exhibits the Janus-face of musical time. Since the advent of the metronome, tempos have been indicated by correlating some durational unit (usually a quarter note) with a unit of clock-time (expressed as beats per minute). Yet a sense of tempo and motion is a hierarchically emergent property of the musical surface, and not simply a product of note-to-note transitions (London 2001, II:5). As David Epstein notes, its reduction into the element of speed per se notwithstanding, tempo "is a consequence of the sum of all factors within a piece - the overall sense of a work's themes, rhythms, articulations, 'breathing', motion, harmonic progressions, tonal movement, contrapuntal activity" (Epstein 1995, 99). The speed allows the overall, integrated bundle of musical elements to flow with a rightful sense. Thus, in the context of musizieren, achieving the right tempo becomes an elusive target, a matter of searching for a fitting characterization, even in musical styles that are familiar and whose performing practices are well documented. Indeed, the transition from late Baroque to early Classical music was marked by a greater sensitivity to "wrong" tempi to the extent that entire symphonic movements by Haydn, Beethoven and especially Mozart can be distorted by a poor choice of tempo (see Blume 1970, 33-35). 
Achieving the right tempo is a perfect example for what Wittgenstein called an "aesthetic puzzle". It involves the possibility of hearing something differently, "just as you may find the head in a puzzle-picture" (M, 9:31). Consider one of Wittgenstein's own examples: the music score indicates the metronome marking of "quarter note $=88$ ", but to play it right nowadays, he says, one must take a faster tempo, "quarter note $=94$ " (MS 110, 281; Z, 37). When he asks "which is the tempo intended by the composer?" it is clear that the question is meant to sound bogus. Presumably, the composer intended that the music would sound "right". Yet merely setting the metronome will not solve the aesthetic puzzle: the proof is in the playing. This is true for different musicians playing the same piece, the same musician playing the same piece on different instruments, or the same musician playing the same piece on the same instrument at different occasions, and certainly when the same piece is played according to two very different performance practices (e.g. romantic versus historically-informed performances of Baroque music). This is even true in the case of clockwork pieces like the second movement of Beethoven's eighth symphony.

Making a choice about tempo is an instance of characterizing, of assembling in a specific field of valence and possibility and contrast. By characterizing we draw in significance, evincing a physiognomy. The attempt to characterize involves, as Juliet Floyd puts it, "the 'coming into view' of a scheme of possibilities available for characterization given a particular mode of characterization" (Floyd 2018, 368). The specificity of characterization means that by characterizing we can "get it just right", can meet or miss its mark, so we patently need to seek the right level and arrangement of elements in order to reveal something, to discover ways in which things and possibilities are. Wittgenstein wrote:

I think it an important \& remarkable fact that a musical theme, if it played <at> (very) different tempi, changes its character. Transition from quantity to quality. $(\mathrm{CV}, 84$. 
The transition from quantity to quality is aesthetic: a transition from the physical ear conception of tempo as speed to the auditory ear conception of tempo as a hierarchically emergent "property" of the musical surface as situated in a culturally entrenched practice. Yet Wittgenstein's twofold point is that the aesthetically "right" pertains only to the latter, and that the transition from quantity to quality is non-reductive.

Searching for the right tempo, for the right characterization of a musical theme, is an example for what Wittgenstein described in his lectures on aesthetics in the 1930 as striving toward an "ideal": "Aesthetic reasons are given in the form: getting nearer to an ideal or farther from it" (M, 9:36). For Wittgenstein, ideals are facilitators of aesthetic discourse. They bring forth reasons that draw our attention to something which can assist us in finding a solution to an aesthetic puzzle (M, 9:33). An aesthetic ideal is not a simple representational standard, not simply a perceived token or a matter of fact that directs us and which we try to duplicate in our artistic activity. According to Wittgenstein, we identify an ideal due to a special role which it plays in the lives of certain people (M, 9:20); "the ideal is the tendency of people who create such a thing" (M, 9:22). It is a prototype (Urbild) in Wittgenstein's restricted sense of a merely regulative idea, the primacy of which is due to its heuristic use in providing the "logical space" for all possible relevant instances (Guter 2015). According to Wittgenstein, "you would need to describe the instances of the ideal in a sort of serial grouping" (AWL, 36). The ideal enables further descriptions, juxtaposing and grouping similar cases, both actual and possible, which collectively yield a "synopsis" or an "overview" (Übersicht) of a system - a collective arrangement, which may show us the point of a given practice. The ideal is precisely "an object of comparison - a measuring rod as it were - within our way of looking at things" (CV, 30).

The ideal, used as a measuring rod, enables and regulates a "protocol" for musizieren (AWL, 37). Yet this is a significantly open-ended protocol. "Aesthetic discussion is like discussion in a court of law," said Wittgenstein, "you don't say 'this is bad or good', but try to clear up circumstances" (M, 
9:31-32). The circumstances are always particular. A reason in aesthetics is "a reason for having this word in this place rather than that; this musical phrase rather than that" (M 9:30). The ideal, which facilitates the aesthetic discussion, is un-hypothetical in the sense of affording a mere picture as a useful device, which "enables [one] to overlook a system at a glance" (M, 9:38). It inheres in the particular case by means of paraphrasing, giving good similes, which result in a collective arrangement of (often surprisingly) similar cases (M, 9:37).

What compels us along with the reasons one begins to offer, set the parameters of the discussion - of what it makes sense to say. Yet these parameters are grammatically related to our ability to always "say much more" in giving reasons (M, 9:13). Wittgenstein insisted that it is hard to rule out anything a priori as it were, from potentially being (an aspect of) an aesthetic reason. According to Wittgenstein, the boundaries for giving reasons in aesthetics are set by means of the "verifying phenomena", which give the reasons adduced their meaning (M 9:43). The aesthetically "right" hinges upon the possibility of being mutually attuned, and the multiform manner of manifesting appreciation, which involves, as Wittgenstein came to realize in his later writings, admitting concepts based on imponderable evidence - evidence that cannot be recognized or explained by reference to rules, yet accepted by those who are experienced with the infinite variation of human physiognomy (Guter 2017). "It is not only difficult to describe what appreciation consists in, but impossible," Wittgenstein reminds us, "To describe what it consists in we would have to describe the whole environment" (LC, I: 20). The verifying phenomena bring aesthetic reasoning to an end; they set a limit for language.

When Wittgenstein says that simultaneity in music is conceptually different from the simultaneity of the clock, this means that while simultaneity in music is geared toward the auditory ear, it is nonetheless casted in the language of informing and communicating. Yet there is a limit to this language: the verifying phenomena by which we determine what makes sense as we engage in 
musizieren. This is precisely the reason why the transition from tempo-as-quantity to tempo-as-quality is non-reductive. This is "the way music speaks", Wittgenstein noted - what is cast in the language of information (Mitteilung) "is not employed in the language-game of informing” (RPP, I: 888; Z, 160161).

We may conclude that, ultimately, Wittgenstein's critique of the Augustinian picture of music can be seen as directed not only at the attempt to give rise to a bogus, nonsensical metaphysical language, which presupposes the primacy of the conceptual framework of memory-time, but also, and perhaps more poignantly, at the philosophical failure of such a view to acknowledge and appreciate the importance of the uniquely conversational, un-hypothetical, human immanence pertaining to the kind of aesthetic recalcitrance wherein the aesthetically "right" marks a limit for our most ordinary language.

\section{References}

Augustine (1948) Basic Writings of Saint Augustine, Vol. 1, ed. Whitney J. Oates. New York: Random House.

Berry, Wallace (1987) Structural Functions in Music. New York: Dover.

Broad, C. D. (1923) Scientific Thought. London: Kegan Paul.

Epstein, David (1995) Shaping Time: Music, the Brain, and Performance. New York: Schirmer. 
Floyd, Juliet (2018) “Aspects of Aspects”, in Hans Sluga and David G. Stern (eds), The Cambridge Companion to Wittgenstein, second edition. Cambridge: Cambridge University Press, 361-388.

Guter, Eran (2015) "The Good, the Bad and the Vacuous: Wittgenstein on Modern and Future Musics", Journal of Aesthetics and Art Criticism 73 (4), 427-439.

Guter, Eran (2017) “Wittgenstein on musical depth music and our knowledge of humankind”, in Gary Hagberg (ed), Wittgenstein on Aesthetic Experience. Basingstoke: Palgrave Macmillan, 217-247.

Hintikka, Jaakko (1996) Ludwig Wittgenstein: Half-Truths and One-and-a-Half Truths, Jaakko Hintikka Selected Papers, Vol. 1. Dordrecht: Kluwer Academic Publishers.

Husserl, Edmund (1964) The Phenomenology of Internal Time-Consciousness. Bloomington, IN: Indiana University Press.

Kusch, Martin (2011), “Wittgenstein and Einstein's Clocks”, in Esther Ramharter (ed), Ungesellige Geselligkeiten / Unsocial Sociabilities: Wittgensteins Umgang mit anderen Denkern /Wittgenstein's Sources. Berlin: Parerga, 203-218.

Kusch, Martin (2015) ““A Branch of Human Natural History’: Wittgenstein's Reflections on Metrology", in Oliver Schlaudt and Lara Huber (eds), Standardization in Measurement: Philosophical, Historical and Sociological Issues. London: Pickering \& Chatto, 11-24.

Langer, Susanne K. (1953) Feeling and Form. London: Routledge and Kegan Paul. 
Levinson, Jerrold (1997) Music in the Moment. Ithaca, NY: Cornell University Press.

London, Justin (2001) “Rhythm”, in Grove Music Online, accessed 10 Sep. 2018, http:///www.oxfordmusiconline.com/grovemusic/view/10.1093/gmo/9781561592630.001.0001/omo$9781561592630-e-0000045963$.

Mabbott, J. D. (1951) “Our direct experience of time”, Mind 60 (238), 153-167.

Gjerdingen, R. O. (1989) "Meter as a mode of attending: a network simulation of attentional rhythmicity in music", Integral 3, 67-91.

Schulte, Joachim (2006) "Wittgenstein on time (1929-1933)”, in F. Stadler and M. Stöltzner (eds), Time and History. Zeit und Geschichte. Frankfurt: Ontos Verlag, 557-567.

Scruton, Roger (1997) The Aesthetics of Music. Oxford: Oxford University Press.

Stern, David G. (1995) Wittgenstein on Mind and Language. New York: Oxford University Press.

Waite, William G. (1980) “Augustine of Hippo”, in Stanley Sadie (ed), The New Grove Dictionary of Music and Musicians, Vol. 1. London: Macmillan, pp-pp. 